\title{
The Physical Tourist
}

\section{Physics in Novosibirsk and Akademgorodok*}

\author{
Natalia Kupershtokh and Alexander Apolonskiy**
}

Novosibirsk, founded in 1893, and Akademgorodok, founded in the 1950s, are places where Soviet and Russian physicists realize long-term large-scale socially-oriented projects. This article provides a walking tour of Akademgorodok, and discusses the unique interaction between Novosibirsk University and dozens of research institutes located in and around Akademgorodok. The tour includes a visit to one of the finest technology parks in Russia.

Key words: Soviet Union; Russia; Siberia; Novosibirsk; Akademgorodok; Novosibirsk State University; technology parks; Sergei Chaplygin; Yuri Kondratyuk; Mikhail Lavrentyev; Yuri Rumer.

\section{Novosibirsk}

Novosibirsk, now the third most populous city in Russia after Moscow and St. Petersburg, is less than 125 years old. Its birth was a byproduct of the TransSiberian Railway. In 1893, a site was chosen where the future railway was to cross the Ob River in Western Siberia. A town at first called Novonikolaevsk, in honor of Tsar Nicholas II, and in 1925 renamed Novosibirsk, or "New Siberia," sprang up on the left bank at that location. After the bridge was completed in 1897 and the first trains began rolling through, the area experienced flourishing industry and trade, rapid population growth, and the development of an urban social environment with cultural, scientific, and educational activities (figures 1, 2, 3).

By the 1930s, Novosibirsk had several education institutes with physics departments. Physicists who graduated from the Novosibirsk State Pedagogical Institute could become teachers at other Novosibirsk colleges and schools. Nonetheless, the

\footnotetext{
* Natalia Kupershtokh is a senior researcher at the Institute of History Siberian Branch of (SB) RAS, Novosibirsk, Russia. Her main interests are history of science, history of research centers in Siberia, and the biographies of famous scientists. She us the author of more than 200 publications and 3 books.

** Alexander Apolonskiy is at the Ludwig-Maximilians-Universität München and MaxPlanck-Institut für Quantenoptik, Garching, Germany. $\mathrm{He}$ is a project coordinator at Laboratory of Attosecond Physics. His main activity is laser development. He is the author of more than 80 articles in peer-reviewed journals, 3 book chapters, and 6 patents.
} 


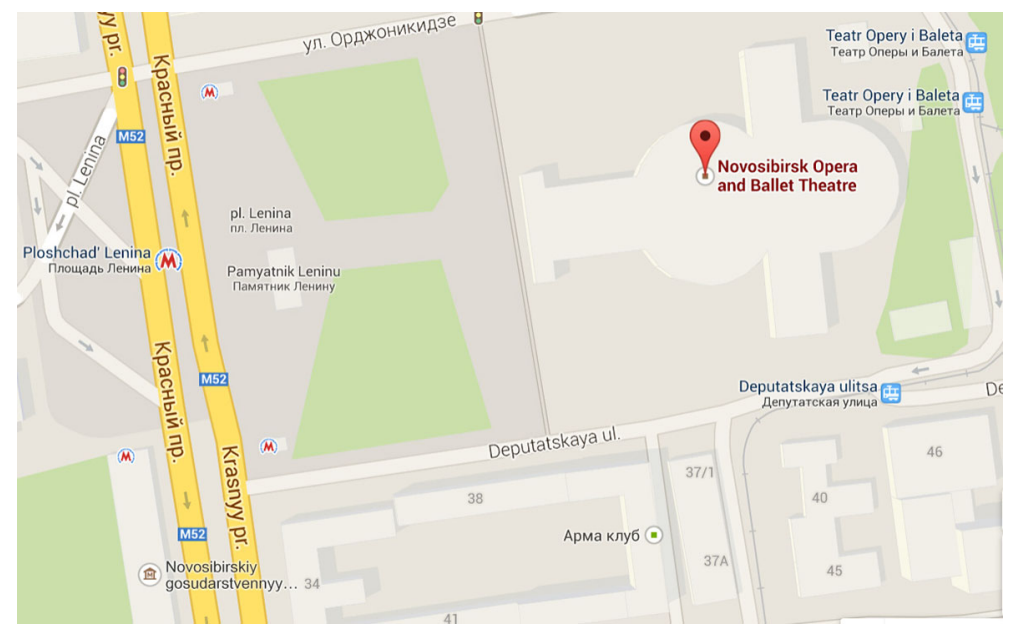

Fig. 1. The center of Novosibirsk, where the Opera and Ballet Theatre is situated. Source/Credit: http://www.google.de.

city of Tomsk-rather than Novosibirsk-was the recognized center of theoretical physics, and the first Siberian research Institute of Physics and Technology was founded at Tomsk University in 1929. But Novosibirsk continued to flourish culturally and scientifically, and the Novosibirsk Opera and Ballet Theatre (1944, figure 3 and the map below), renovated in 2005, is the largest theatre in Russia.

One of Novosibirsk's most famous scientific pioneers was the mathematician and engineer Yuri Kondratyuk (1897-1942), who spent only a few years in Novosibirsk (1927-1932), but who left a strong impact on ideas about space exploration. We have only sketchy details of Kondratyuk's life story. He was born Alexander Shargei and studied engineering in St. Petersburg (then Petrograd) before being drafted into the Tsarist army. After the 1917 revolution, he attempted to flee Russia but was turned back. In 1921, to escape arrest, he appropriated the passport of a student named Yuri Kondratyuk, who had died of tuberculosis, and eventually settled in Novosibirsk in 1927. In 1929, he published at his own expense a book titled The Conquest of Interplanetary Space, which he had first written in 1916 in St. Petersburg under the name Shargei. ${ }^{1}$ Several of the ground-breaking ideas from this book were later put into practice, including space stations, oxygenhydrogen fuel, the use of solar energy, shielded space vehicles, and use of the gravity of celestial bodies for laying out spacecraft trajectories. Kondratyuk also proposed a method for lunar landings in which a small craft would leave a mother ship in lunar orbit to ferry its crew to the surface and back-a technique later referred to as Lunar Orbit Rendezvous or LOR. Forty-five years after the Apollo lunar landings, it is all too easy to see this method of landing a human crew on the Moon as the only sensible way. But this was not obvious at first; indeed, initially 




Fig. 2. Yuri Kondratyuk (source: http://en.wikipedia.org/wiki/Yuri_Kondratyuk) and the Museum of Yuri Kondratyuk (Sovetskaya Street 24, see the map). Source: E. M. Schukina. "The Earth Projection of One Cosmic Fate," Science Firsthand, 37, no. 1 (2011), 77 (in Russian). 


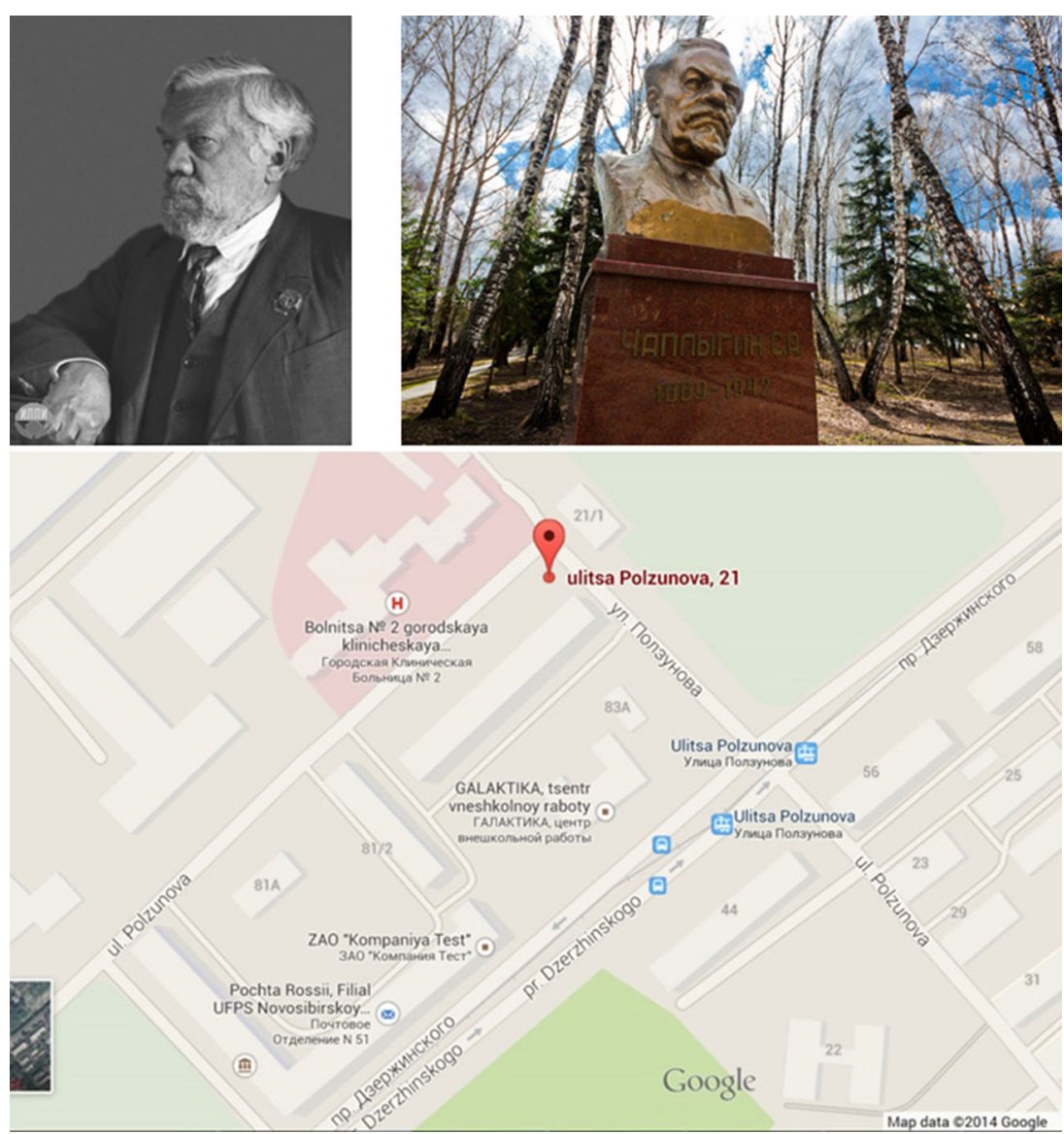

Fig. 3. Left S. Chaplygin; right Chaplygin's monument at the SibNIA shown in the map. Sources: http://www.warheroes.ru/hero/hero.asp?Hero_id=8999. Credit: Russian international project Country's Heroes; http://photos-media.ru/index.php?id=18.

NASA had rejected the idea of bringing two vehicles together in space above the Moon as too difficult. ${ }^{2}$ Kondratyuk's talent was evident in many other areas. He designed a 13,000 ton wooden grain silo called Mastodon, which was built in 1930 and featured a grain elevator without a single nail-nails were hard to find in Siberia in those times-which remained in operation until the end of the twentieth century. He also built a wooden suspension bridge in Novokuznetsk and designed a giant wind power station, never built, for Crimea.

In 1930, he was arrested on false charges, convicted under the notorious Article 58 of the Soviet Penal Code dealing with "counter-revolutionary activities." One of the absurd pieces of evidence cited against him was the lack of nails used in the Mastodon, which supposedly revealed that Kondratyuk wanted the structure to 
fail. He was sentenced for three years to a labor camp, though thanks to his engineering abilities he ended up instead in a sharashka, or research facility prison.

Kondratyuk joined the Red Army in 1941 and died the following year, though like many other Soviet people who fought and died in battle during World War II the exact place and date of his death are unknown. But he is commemorated in several places in Novosibirsk. A square in Novosibirsk's Zheleznodorozhnyj district and an aerospace lyceum (high school) bear his name. In 1993, the museum of Yuri Kondratyuk opened its doors at Sovetskaya 24 (see the map in figure 2), with 7,500 exhibits including documents, photos, and models of his spacecraft designs.

After the German invasion of the Soviet Union in June 1941, the Soviet Government decided to establish a defense-oriented scientific and industrial center in Novosibirsk, which would not only manufacture military equipment and weapons but also ensure further development of military technology. In August 1941, the Novosibirsk division of the Central Aerospace Institute came into being. A team of Soviet scientists evacuated from the western part of the USSR was put in charge of the division under the leadership of Sergei Chaplygin (1869-1942, figure 3).

Chaplygin studied at Moscow University at the Department of Physics and Mathematics, where he acquired a life-long interest in mechanics. His first research paper, "About the Movement of Heavy Objects in Incompressible Liquid," was accepted as his university thesis and awarded the Gold Medal of Moscow State University (MSU). His doctoral thesis, "Gas Jets" (1903), proposed a technique to study gas jets at sub-sound velocities. In 1935, at the Fifth Volta Conference in Rome, his contributions to the study of gas dynamics became widely known, standard reference material for airspace engineers, designers, and developers. Starting in 1941 at the Central Aerospace Institute in Novosibirsk, he was entrusted with the critical mission to build an aero- and hydrodynamic base for aircraft manufacture and testing. Chaplygin died in 1942. In 1946, the Siberian division of the Institute was reorganised as the independent Siberian Aeronautical Research Institute (SibNIA, Dzerzhinsky District), now named after Chaplygin, which has become the largest aeronautical research center in the east of the country. He is commemorated at several locations throughout Novosibirsk. A memorial plaque bearing Chaplygin's name is installed on the first building of SibNIA, his sculpture stands in the main alley of the Institute memorial park (Polzunov Str. 21, see map), and a street in Novosibirsk bears his name.

Wartime conditions during 1941-1945 imposed an urgent need to accelerate the study and exploration of Siberian natural resources to mobilize the entire national industry for the defense of the country. In October 1943, the Council of People's Commissars of the USSR issued a directive ordering the establishment of the West Siberian branch of the Academy of Sciences (AS) of the USSR in Novosibirsk. A technical physics subdivision was created in this branch and then a department; this was later transformed into the first academic institute in Novosibirsk related to physics, the Institute of Radiophysics and Electronics (IRE, 1957, figure 4). It was headed by the outstanding Soviet theoretical physicist Yuri B. Rumer (1901-1985, figure 4). 

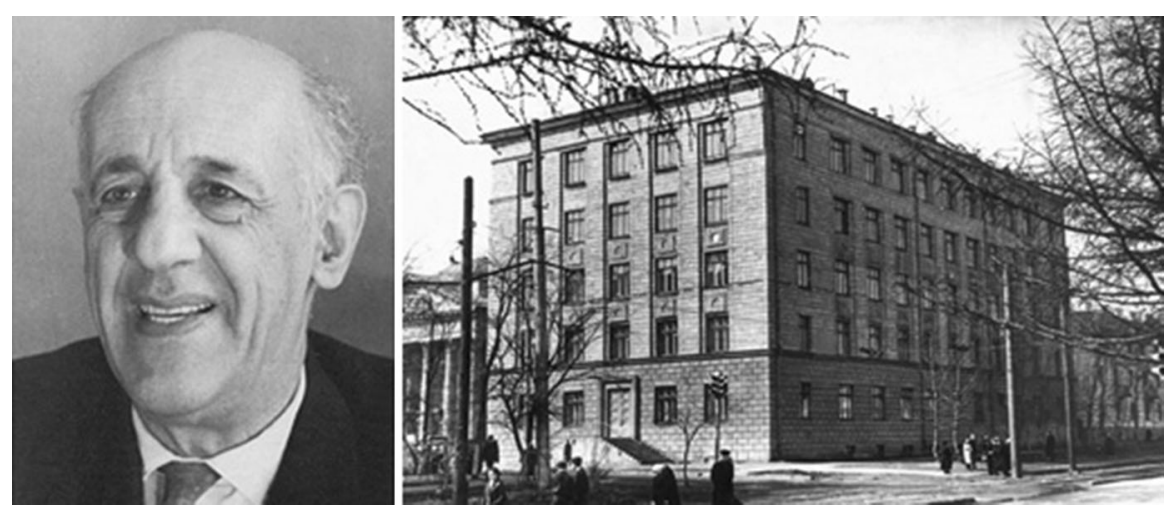

Fig. 4. Yuri Rumer and the first physical research institute in Novosibirsk, the Institute of Radiophysics and Electronics (IRE, Michurina Street 23), which he headed in 1957-1964. Source: Yuri Borisovich Rumer: Physics, Twentieth Century, ed. A. G. Marchuk (Novosibirsk: ARTA, 2013) (in Russian).

Rumer graduated from the Department of Physics and Mathematics at the Moscow State University in 1924. While at the university, he maintained close ties with "Luzitania," a school of mathematics whose followers were inspired by the work of Nikolai Luzin. Rumer spent two years (1926-1928) on scientific leave at the Higher Polytechnic School in Oldenburg, Germany, then worked in 1929-1932 on problems of quantum mechanics in Göttingen as an assistant to Max Born. On his return to Moscow, Rumer worked at the Moscow State University and at the Physics Institute of the Academy of Sciences of the USSR. His monographs included "Introduction to Wave Mechanics" (1935) and "Spinor Analysis" (1936). Together with another famous physicist, Lev Landau, he wrote several classical works on the theory of cosmic ray showers and on the theory of solids. Their popular book, What Is Relativity?, was translated into more than twenty languages.

At the end of the thirties, Rumer was arrested together with Lev Landau as his accomplice. In prison, Rumer was thrown into the same cell as Sergei Korolev, the future lead designer of the Soviet space program, and Andrei Tupolev, a rocket engine and airplane designer. Later, in a sharashka, Rumer worked on suppressing the flutter and shimmy effects in airplanes. Korolev was a point of contact between Kondratyuk and Rumer: in the mid-thirties, Kondratyuk rejected Korolev's invitation to join him at the Jet Propulsion Research Institute, fearing an investigation by the GPU, the Soviet secret police. Rumer contributed to aeronautics and electron gas magnetism and authored a series of pioneering publications on a fivedimensional generalization of relativity (five-dimensional optics*). Later, Rumer

* English-speaking readers can find extended explanations in A. Jadczyk "START in a Five-Dimensional Conformal Domain," Advances in Applied Clifford Algebras 22 (2012), 689. 

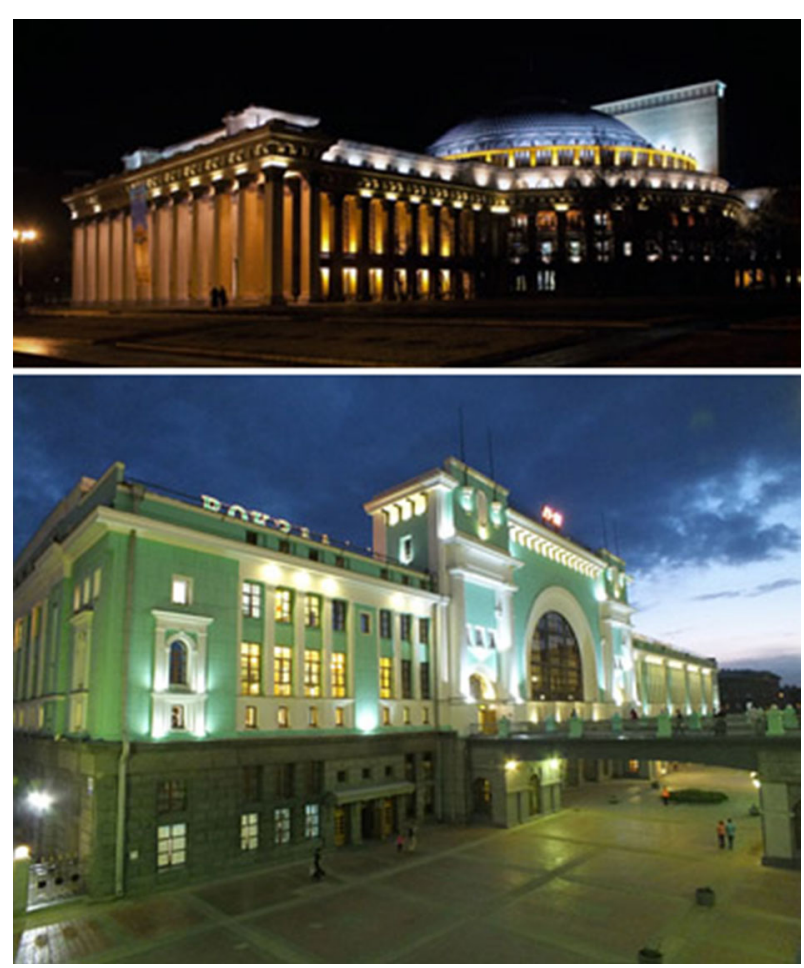

Fig. 5. Night views of modern Novosibirsk: the Opera and Ballet Theatre (top) and central railway station (bottom). Credits: G. Nikitina; livebloger.ru.

spent 1948-1950 exiled in the Siberian town of Eniseysk, from which he was transferred back to Novosibirsk thanks to the efforts of the President of the Academy of Sciences of the USSR, Sergei Vavilov.

After Stalin's death in 1953, Academicians Lev Landau, Mstislav Keldysh, Boris Stechkin, and Igor Tamm interceded with the authorities on Rumer's behalf, and he was employed at the West Siberian Branch of the Academy of Sciences. He was reinstated as a professor and doctor of sciences in physics and mathematics; after 1954, he headed the Department of Technical Physics at West-Siberian Branch of the Academy of Sciences. In 1957-1964, Rumer worked as the Director of the Institute of Radio-Electronics (IRE). The institute is focused on the following subjects: theoretical physics (applied electrodynamics), electron phenomena at ultra-high frequencies, cathode electronics, and the physics of gas discharge. IRE also initiated and organised studies and development in the fields of ultrahigh frequency electronics, the physics of lasers and laser radiation, as well as their practical application. The first Siberian gas laser was demonstrated there in the beginning of 1960s by Grigory Krivoshchekov, Yuri Troitsky, Nina Goldina, 
Yuri Kolomnikov, Vasiliy Klementyev, and Veniamin Chebotayev (figure 13). As the institute grew larger, Rumer eventually found that he was not able to manage it all himself, and eventually resigned as IRE Director. The Institute of Radiophysics and Electronics was initially located at Michurin Street 23 (figure 4). The hundredth anniversary of Rumer's birthday was marked with a memorial plaque installed on the side of the building.

Novosibirsk is now one of the most industrialized cities of Siberia, its population exceeding 1.5 million. Places of general interest include the Novosibirsk Zoo, one of the best in Russia (Timiriazeva Street 71/1); the central railway station and the Opera and Ballet Theatre (Krasny prospekt, 36), the largest in Russia (figure 5).

\section{Novosibirsk's Science Center: Akademgorodok}

In the 1950s and 1960s, many new research institutions and research centers were founded in the Soviet Union. These included a Siberian branch of the Academy of Sciences of the USSR (SB AS USSR), which was created in 1957 backed by the Soviet political leader Nikita Khrushchev. The major aims of this branch were to further fundamental research through interdisciplinary studies, develop technological innovation to be transferred to industry, train highly qualified specialists in modern departments of knowledge, and study and explore the natural resources of the eastern regions of the USSR.

The most ambitious new research institution was Akademgorodok-“Academy Town," or small scientific and educational city—on the outskirts of Novosibirsk. To the best of our knowledge, Akademgorodok was the first example of such a city, combining a high-profile university, dozens of research institutes, and design bureaus. The idea of a research center based on an academic model to be located in Siberia was proposed by academicians Mihkail Lavrentyev, Sergei Sobolev, and Sergei Khristianovich (figure 6). Although Akademgorodok was initially envisioned as a defense project to build a back-up research structure in the middle of the country-geographically it is about equidistant from Russia's east and west borders-after the "thaw" initiated by Khruschev, Akademgorodok's founders convinced the government to give non-military research the highest priority.

Today, the Novosibirsk Scientific Center, also known as the Novosibirsk Akademgorodok, is the largest research centre of the Siberian Branch of the Russian Academy of Sciences (figure 7, 8). Erected during the course of ten years forty kilometers from the center of Novosibirsk, just beyond the city limits, it lies in a forest at the shores of the $\mathrm{Ob}$ water reservoir (also called the $\mathrm{Ob} \mathrm{Sea}$, figures 7,8). The landscape of Akademgorodok was designed to preserve the natural environment. Akademgorodok is officially a part of Novosibirsk, in the so-called Sovetsky Rayon or district. It is divided into six living zones: A, D, Sha, Nizhnaya Eltsovka; Shlyuz and Levyi Bereg and, in total, has about 130,000 inhabitants. 

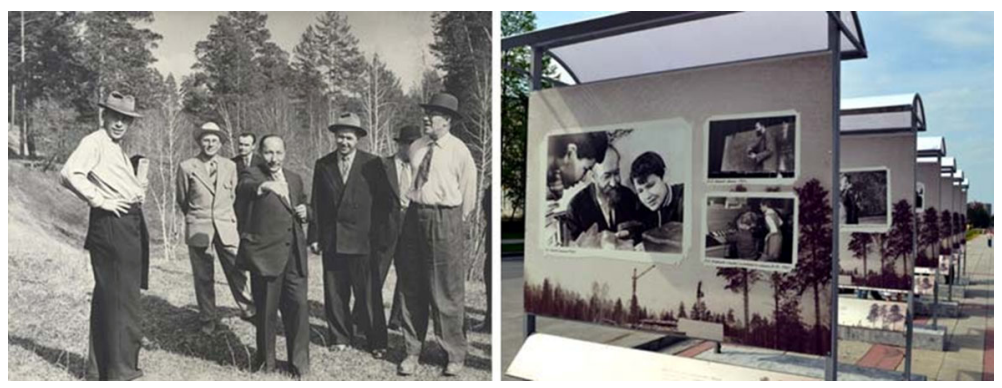

Fig. 6. Left The founders of Akademgorodok at the site of the new scientific center; on the far right is Mikhail Lavrentyev. Right A permanent open-air photo-exhibition devoted to the history of Akademgorodok, located on Koptyug Ave. Credits: R. I. Akhmerov; the author (NK).

Akademgorodok was envisioned as a technology park from the very beginning. Its main features are the close proximity of a university, many institutes with different specializations, design bureaus, and production facilities associated with the institutes, with low-rise residential areas integrated into the natural landscape (figure 7). Akademgorodok's design attempted to take account of the leading trends in science, as well as the experience of other research centers in Russia and abroad. Its logo (figures 7,8 ) shows the Greek letter sigma-used in mathematics to denote summation-emblazened over a symbol for a shock wave. The sigma suggests a synergy among a broad range of disciplines mutually strengthening each other; the shock wave suggests that the establishment of this research center in Siberia is a flash of lightning bringing into existence a powerful new entity.

The scientists who wanted to work in this new city of Siberian science were provided with both comfortable work conditions and possibilities for recreation and social life. Luminaries of Soviet science were offered opportunities to come to the institutes with their students and help shape the institutes' directions. Media attention at the end of 1950s played a major role in acquainting university graduates in Moscow, Leningrad, Kiev, L'vov, and other cities with Novosibirsk and in encouraging them to relocate there. As a result, Akademgorodok during the 1960s became the country's youngest research center.

The institutes at Akademgorodok now cover practically all areas of modern science: mathematics, mechanics, physics, geophysics and geology, chemistry, biology, economics, and the humanities. In 1961, the Novosibirsk Scientific Centre had over twenty research institutes, while today their number is thirty-five. Several physical institutes are named after their founders, who were leaders of Siberian fundamental science. These include the S. Kutateladze Institute of Thermal Physics, the G. Budker Institute of Nuclear Physics (BINP), the S. Khristianovich Institute of Theoretical and Applied Mechanics, the A. Rzhanov Institute of 

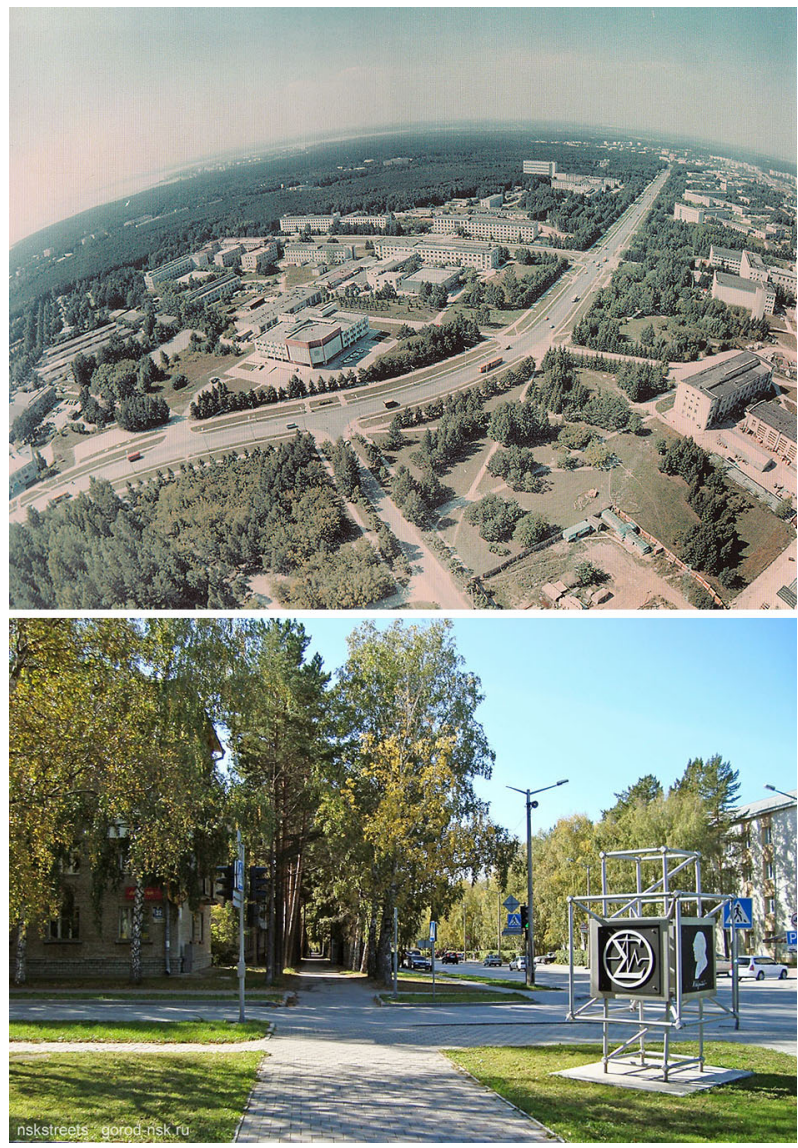

Fig. 7. Top An eagle's eye view of Akademgorodok. Other aerial pictures can be found at http:// gelio.newsib.ru/post/932/. Bottom the intersection of Morskoy Avenue and Tereshkova Street. Credits: R. I. Akhmerov; NK.

Semiconductor Physics, and the M. Lavrentyev Institute of Hydrodynamics. The institutes on the average each have 200-300 employees, with the exception of the BINP, which has about 3,000.

Akademgorodok soon became known worldwide. It hosted large international conferences and was visited by government officials, noted scientists, and artists. The Novosibirsk State University and the School of Physics and Mathematics opened at the same time as the institutes, ensuring that the Novosibirsk Scientific Center evolved from the very beginning as a complete scientific and educational complex. 

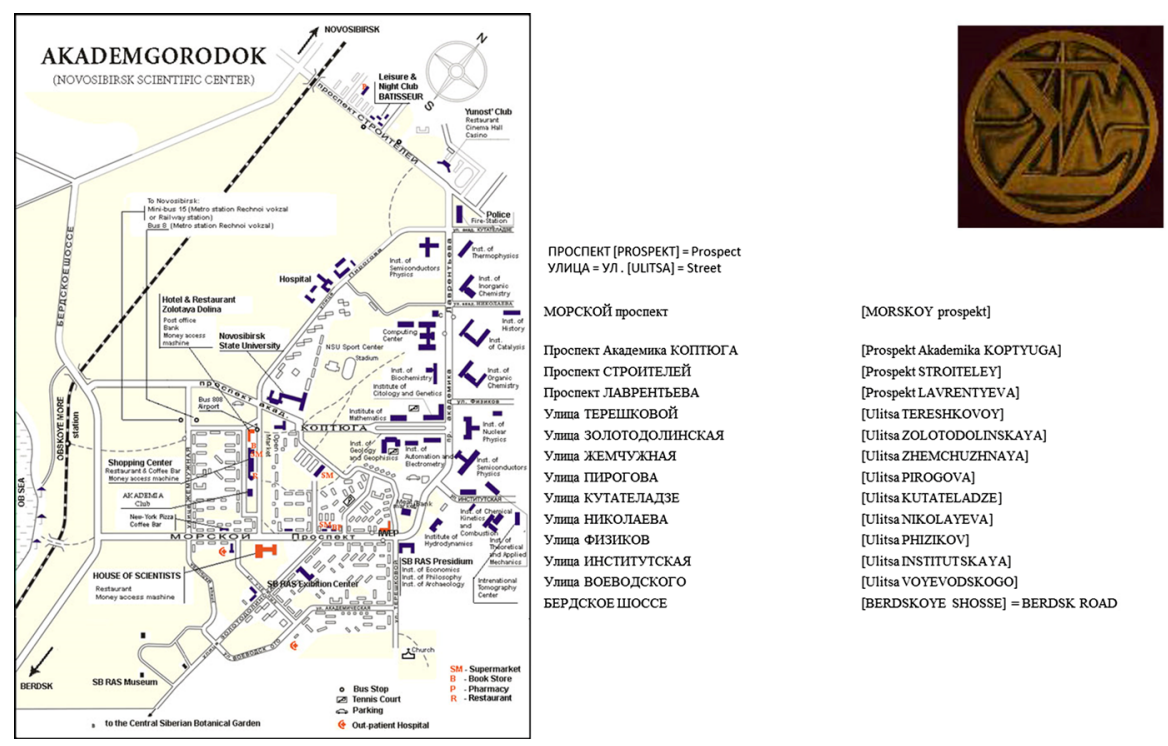

[MORSKOY prospekt]

[Prospekt Akademika KOPTYUGA]

[Prospekt STROITELEY]

[Prospekt LAVRENTYEVA]

[Ulitsa TERESHKOVOY]

[Ulitsa ZOLOTODOLINSKAYA]

[Ulitsa ZHEMCHUZHNAYA]

[Ulitsa PIROGOVA]

[Ulitsa KUTATELADZE]

[Ulitsa NIKOLAYEVA]

[Ulitsa PHIZIKOV]

[Ulitsa INSTITUTSKAYA]

[Ulitsa VOYEVODSKOGO]

[BERDSKOYE SHOSSE] = BERDSK ROAD

Fig. 8. A map of Akademgorodok with the emblem of Novosibirsk Scientific Center (top right); a 3-D view taken from a helicopter above the intersection of Lavrentyev and Koptyug avenues can be found at aircam.pro/3d-photo/academ2/. Source: http://www.isp.nsc.ru/symposium/location. html.

\section{A Tour of Akademgorodok}

Akademgorodok is accessible from the city of Novosibirsk by a modern road (the Berdsk highway); visitors enter on Stroitelei (Russian for "builders") Avenue. Akademgorodok owed the rapid construction of its infrastructure to the firm Sibakademstroi, and one of its main streets is named after the head of Sibakademstroi, General Nikolai Ivanov. The map shown in figure 8 will help to make the tour. The Palace of Youth ("Yunost") is located on Stroitelei Ave. The name of this recreation and cultural center, strange to the modern ear, harks back to the beginning of the sixties when the majority of Akademgorodok's population was very young. Just past the Palace of Youth, Stroitelei Avenue merges into one of the central thoroughfares of Akademgorodok, Academician Lavrentyev Avenue, named after the founder of the Siberian Branch of the Academy of Sciences of the USSR and the Novosibirsk Scientific Center. A billboard inscribed with the words of Mikhail Lomonosov, "Russian power shall accrue from Siberia," appears above the avenue, quoting a prediction made by Lomonosov after learning the results of the First and Second Kamchatka Expeditions initiated by Peter the Great and organized by the RAS. The Second Expedition was especially impressive and continued for a decade (1733-1743), amassing an extensive store of information on the ethnography, geography, and natural resources of the Siberian region. 
Academician Lavrentyev Avenue and its environs are the home of Akademgorodok's research institutes. The Kutateladze Institute of Thermal Physics was founded in 1957. Thermal physics (an amalgam of thermodynamics, statistical mechanics, and kinetic theory that examines the complex interaction of thermodynamic, gas-dynamic, and electrodynamic processes in solids, gases, liquids, and plasma) had enjoyed rapid progress in the first half of the twentieth century; this was the world's first institute that specialized in the subject. This institute was organized by Ivan Novikov (born in 1916), now a member of the RAS and a specialist in thermal physics, thermodynamics, hydrodynamics, and power engineering. He was a trailblazer in the new scientific field involving technological applications of thermodynamics. Novikov and his colleagues developed the theory of optimization of complex energy systems in what is known as the NovikovCurzon-Ahlborn theory. In 1964, Novikov returned to Moscow following a disagreement with Lavrentyev, the President of the Siberian Academy of Sciences. Between 1964 and 1986, the Institute was headed by Samson Kutateladze (1914-1986). Upon completion of a course at a correspondence industrial institute, Kutateladze worked at the Polzunov Central Institute of Boilers and Turbines, fought in the war, and taught at the A. Krylov Marine Academy. Kutateladze examined heat exchange in two-phase media in his doctoral thesis (1952), and his first monograph, Foundations of Heat Exchange Theory (1954), ran through four editions in USSR and abroad, gaining him international recognition as an outstanding thermal physicist. The Kutateladze burn-out theory and Kutateladze criterion are internationally recognized scientific terms. In 1994, the Institute of Thermal Physics was named after Samson Kutateladze and memorial plaque was installed on its building. His name was also given to one of the streets in Akademgorodok. At present, the institute (headed by Sergei Alekseenko) is one of the best research centers for the study of heat exchange and physical hydro- and gas dynamics, conducting fundamental studies in a wide range of fields of hydrodynamic stability and turbulence, multiphase flows, and low-temperature plasma. World-class results have been demonstrated in shock wave propagation effect in gases. Attention is also paid to innovation and applied research, especially ecologically clean power and power conservation. Modern energy-efficient and energy-saving technologies and products are under development.

Turning from Lavrentyev Avenue onto Academician Nikolaev Street-named after the inorganic chemist Anatoli Nikolaev, the first Director of the Institute of Inorganic Chemistry-and following it almost to the end, one finds the Museum of the Siberian Branch of the Russian Academy of Sciences (at number 8). Until 2012, the Museum was located in the house of Academician Lavrentyev in Zolotodolinskaya Street. The displays and exhibits provide an interesting overview of the history of Akademgorodok and of its scientific life. The museum, proposed by Lavrentyev himself, opened its doors in 1991 and has become a well-known Siberian research and educational center. 

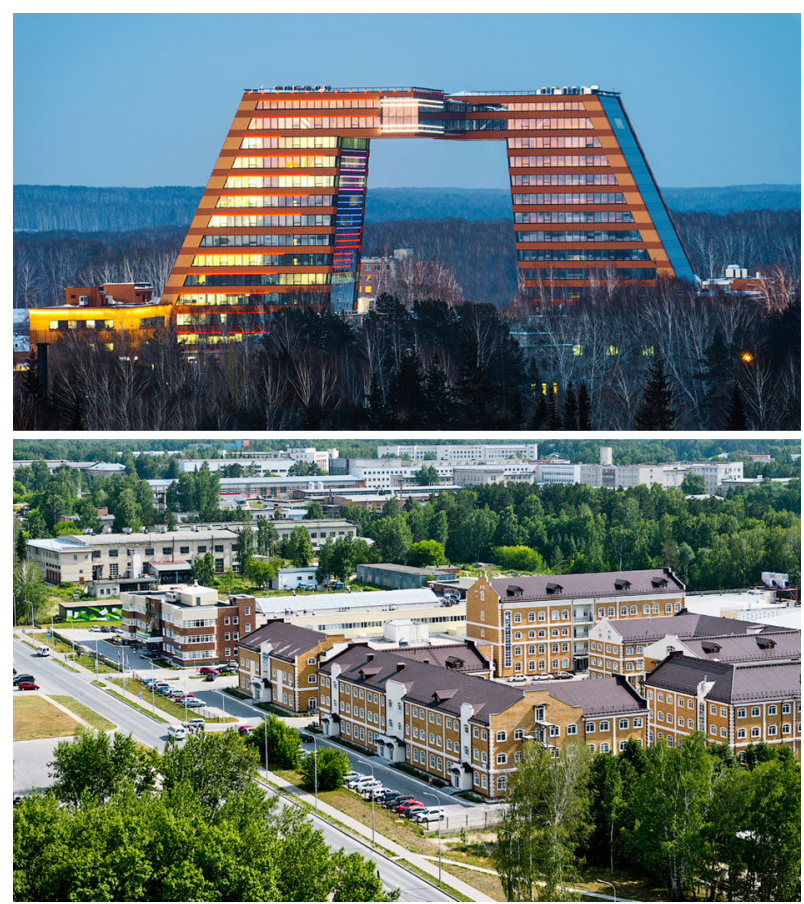

Fig. 9. Technology Park (Technopark) in Akademgorodok. Top the IT towers. Bottom the buildings occupied by the companies producing physical and chemical products. Source: http:// gelio-nsk.livejournal.com.

Academician Nikolaev Street leads us to the recently constructed modern technology park, AcademPark or Technology Park (Technopark) (figure 9). Its creation in Akademgorodok was all but inevitable. At the beginning of the twentyfirst century, more than 120 high-technology companies had been spun off by the institutes of the Novosibirsk Scientific Center and were active in and around Akademgorodok. The major companies formed an association, SibAcademInnovation, and a non-profit partnership, SibAcademSoft. The need became acute for a large technology center in order to coordinate the activities of participating companies and organizations, to facilitate the formation of new technology clusters, and to serve as an intermediary between scientists, business, and the government in bringing innovation to practical use. SibAcademSoft proposed construction of an IT park in January 2005 on the occasion of a visit by the Russian President Vladimir Putin to Akademgorodok. The Russian Government officially launched the project of Akademgorodok Technology Park in March 2006. The Akademgorodok Technology Park served as a fresh stimulus to the development of the Novosibirsk Scientific Center, assisted in research and development of new products and technologies, and facilitated IT business. 
The Technology Park was conceived as a complex of facilities situated around Academician Nikolaev and Ingenernaya streets. A virtual tour of the Park is available at its web site (http://www.academpark.com/en/). The central structure is to consist of three towers, of which two have already been commissioned (figure 9). At the beginning of 2012, one of the key elements of the Park's infrastructure and the core of its IT cluster, the Center of Information Technologies, was officially inaugurated at the Akademgorodok Technology Park.

The first technology cluster within the Technology Park-Instrument Engineering-was created with the participation of Uniscan Company. The cluster's infrastructure includes a Center of Technology Services, engineering and manufacturing facilities for contract production, and a business incubator. The Centre of Technology Services is responsible for satisfaction of all technology needs of instrument engineering innovation companies and projects, from the prototype development stage to industrial production. Currently, Technology Park has four clusters: Instrument Engineering, Information Technologies, Biomedical, Nanotechnologies and New Materials. Dozens of resident companies operate within each. Their total number is 263 , and the majority (143) reside in Technology Park facilities. The complete list of resident companies is available at the Park's web site (aircam.pro/3d-photo/academ2/). Technology Park acts as a business incubator for young scientists and entrepreneurs. Its summer and winter workshops are attended by aspiring businessmen, as well as staff and postgraduate students working at institutes of the Siberian Academy of Sciences. Authors of business or technology proposals can also participate in these activities. In 2012, the Technology Park hosted the regional phase of the all-Russian Competition of Innovative Business Technologies. Among the winners were several start-up projects ready for investment whose projects proposed many innovative products and technologies, such as biodegradable plastics from renewable raw materials, fiber-optical temperature sensors, high-friction materials for ice, waste water treatment, ion-exchange technology for oxygen production, and computerized sign language translation systems.

We continue our tour of the scientific center by returning from Academician Nikolaev Street back to Academician Lavrentyev Avenue. The Budker Institute of Nuclear Physics (BINP) is one of the world-leading organizations in the field of high-energy physics, controlled thermo-nuclear fusion, and applied physics (figure 10). The processes explored by the physics of the tiniest particles turn out to be closely related to those that govern the formation and evolution of the universe. INP was founded in 1957 following the proposal of Igor Kurchatov, the Director of the Moscow Institute of Atomic Energy. Kurchatov recommended that this new institute be led by his young follower and colleague Gersch Budker, who was not even forty years old at the time. Budker (1918-1977), a graduate of the Moscow State University who fought in World War II, was decorated with the Stalin Prize (1949) for his research work within the Soviet atomic project. During the 1950s, Budker established with Kurchatov's backing a laboratory to develop new particle 


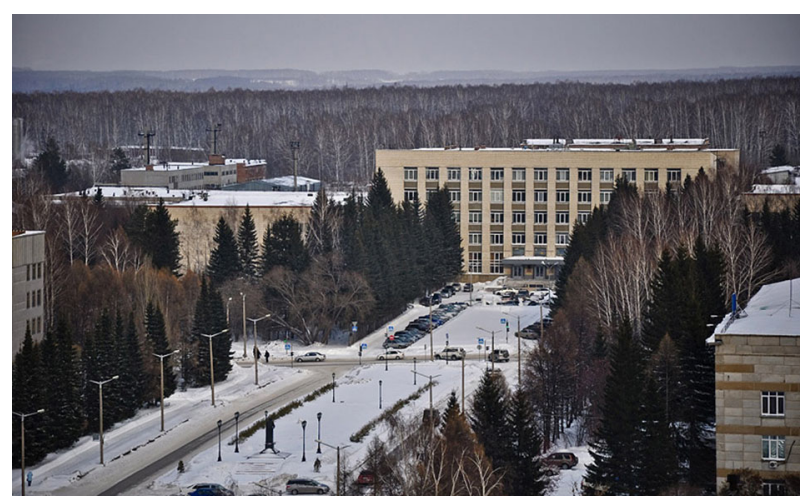

Fig. 10. Budker Institute of Nuclear Physics. Source: http://gelio-nsk.livejournal.com.

acceleration techniques at the INP. Akademgorodok preserves with great care the memory of Academician Budker. ${ }^{4}$ His name was given to the Institute of Nuclear Physics - a memorial plaque is installed on its main building - a lecture hall at the Novosibirsk State University, and a street in Akademgorodok. The second and current director of the institute is Alexander Skirinski.

Over the fifty-year history of their institute, the INP's scientists have demonstrated world-class results. In the domain of high-energy physics, Gersh Budker, Lev Barkov, Nikolai Dikansky, Gennadi Kulipanov, Alexander Skrinsky, Vladimir Balakin, Vasilii Parkhomchuk, Veniamin Sidorov have carried out pivotal work on the design and development of accelerators with colliding beams, as well as on their application in the physics of elementary particles (first two images in figure 11). The classical principle of plasma containment in a trap with an open magnetic field proposed by Budker has been implemented in many modern versions by Dmitri Ryutov, Eduard Kruglyakov, and Gennadi Dimov (bottom of figure 12).

In 1961, the institute began construction of VEP-1, the first particle accelerator in the Soviet Union to use two colliding particle beams to increase the effective collision energy. BINP contributed toward the construction of CERN's Large Hadron Collider by providing equipment, including beamline magnets, for the device that was involved in the discovery of the Higgs boson in 2013. Other scientific activities include study of weak interactions in atoms (L. Barkov, figure 12), development of free-electron laser operation in UV (G. Kulipanov, figure 12) and mid-IR ranges (Nikolai Vinokurov). The Siberian Snake, proposed in 1974 by Yaroslav Derbenev and Anatoli Kondratenko to avoid the depolarization problems of beams of spinning electrons or protons, has become a powerful tool for accelerator physicists. Another noteworthy scientist at the institute is Boris Chirikov, whose review on the subject of chaos theory has one of the highest number of citations among all Soviet/Russian papers. ${ }^{3}$ Nowadays, the institute 

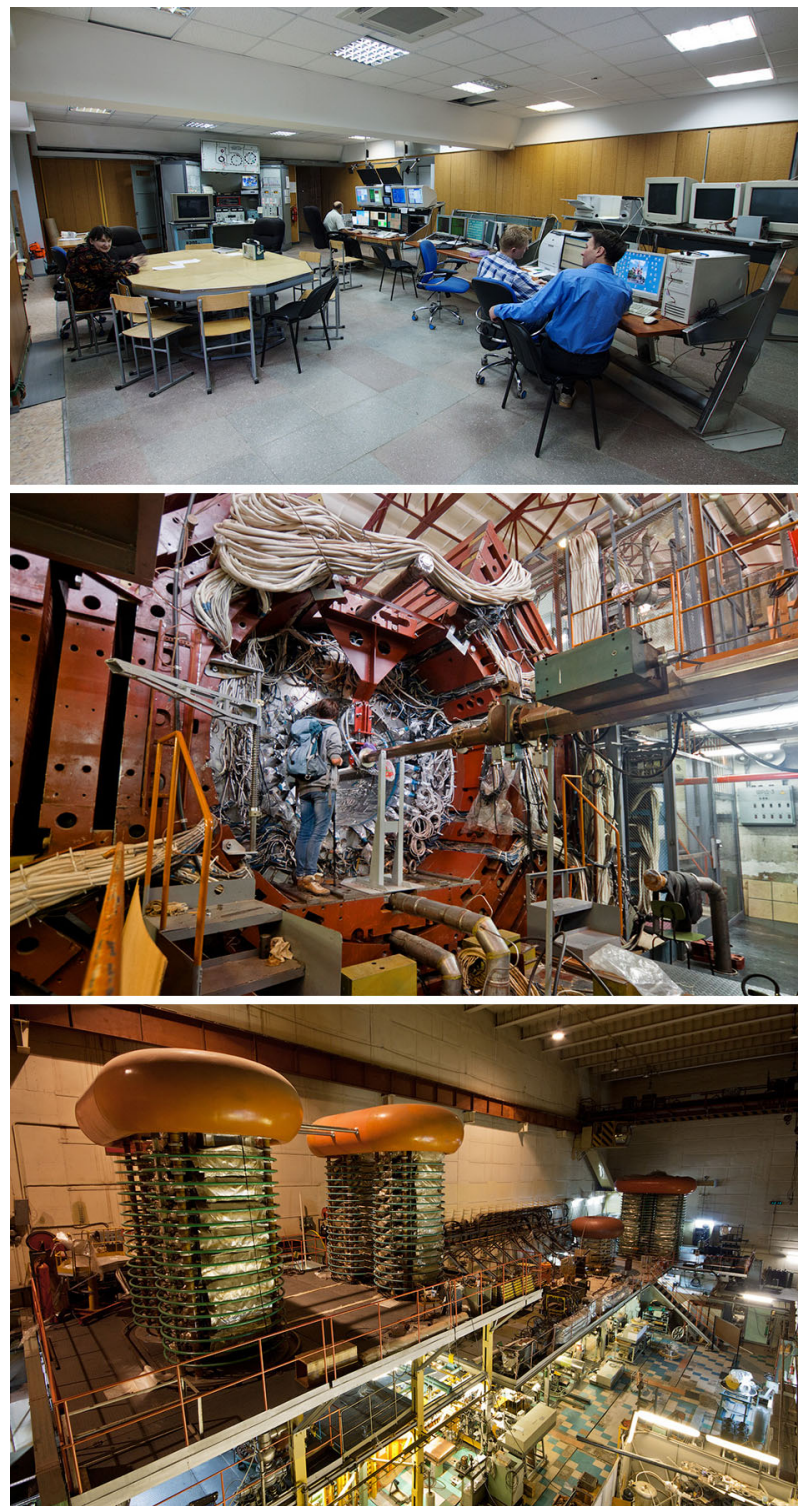

Fig. 11. The VEP-4 accelerator at the Budker Institute of Nuclear Physics. Top the control room. Middle the KEDR detector (note the standing man in the middle for scale). Bottom GOL-3 (open plasma trap) for studying high-temperature plasma. Credit: V. Makhorov. 

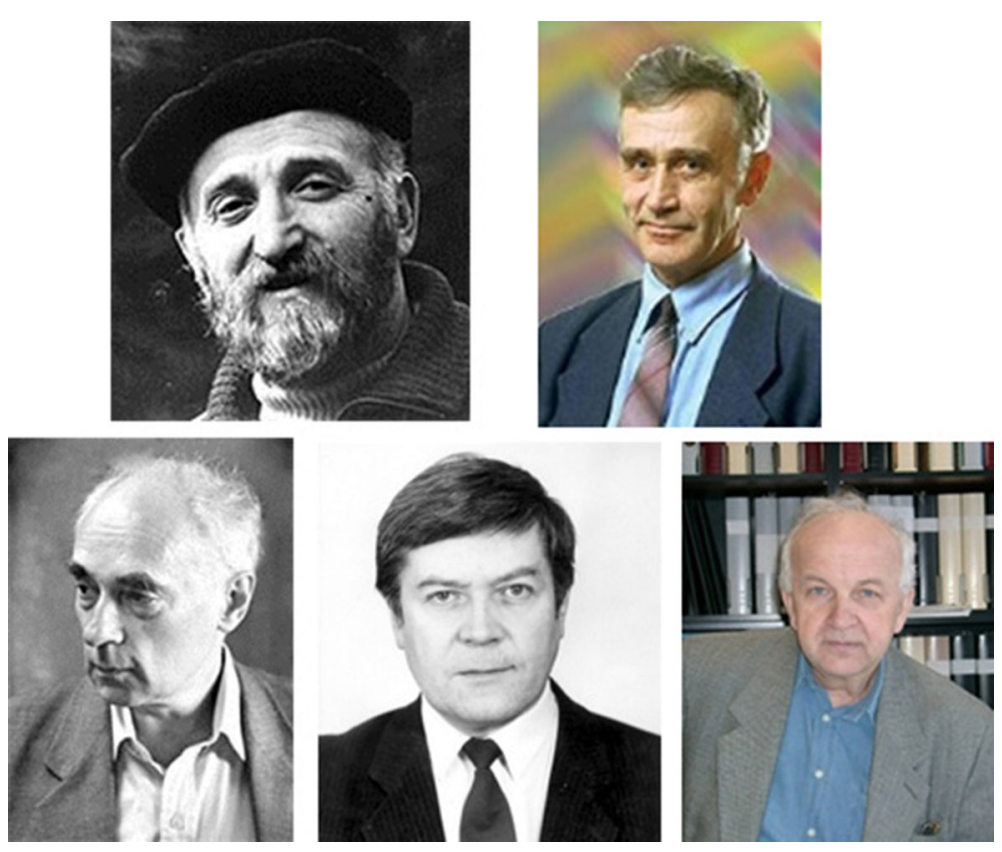

Fig. 12. Five key individuals of the Budker Institute of Nuclear Physics, from left to right: Gersh Budker (its first director), Alexander Skirinski (the second and current director), Dmitri Ryutov, Lev Barkov, Gennadi Kulipanov. Source: http://www.ras.ru.

comprises multiple buildings, including a mechanical plant for production of bulky and complex parts. BINP is the only institute within RAS able to support its fundamental research by commercial sales of hi-tech products, including particle accelerators, magnets, RF cavities, etc.

Almost in front of BINP along Academician Koptiug Avenue, one can see the Institute of Automation and Electrometry, founded in 1957. Its specialization was in line with the needs of the time in the fields of aerospace, industrial, and radio-electronic equipment. The institute was tasked with development of automatic measurement instrumentation for collection and processing of information.

The organization of the new institute was entrusted to Konstantin Karandeev (1907-1969), a well-known specialist in electrical engineering. His name is inseparably linked with the making and development of modern measurement theory and with a number of important areas of instrument engineering. The next institute director, Yuri Nesterikhin, pioneered the direction of automatic control of various technology processes and physical experiments. Today, the Institute headed by Anatoli Shalagin focuses its research on physics and technology. The physical department has been delivering world-class results in study of turbulence, 


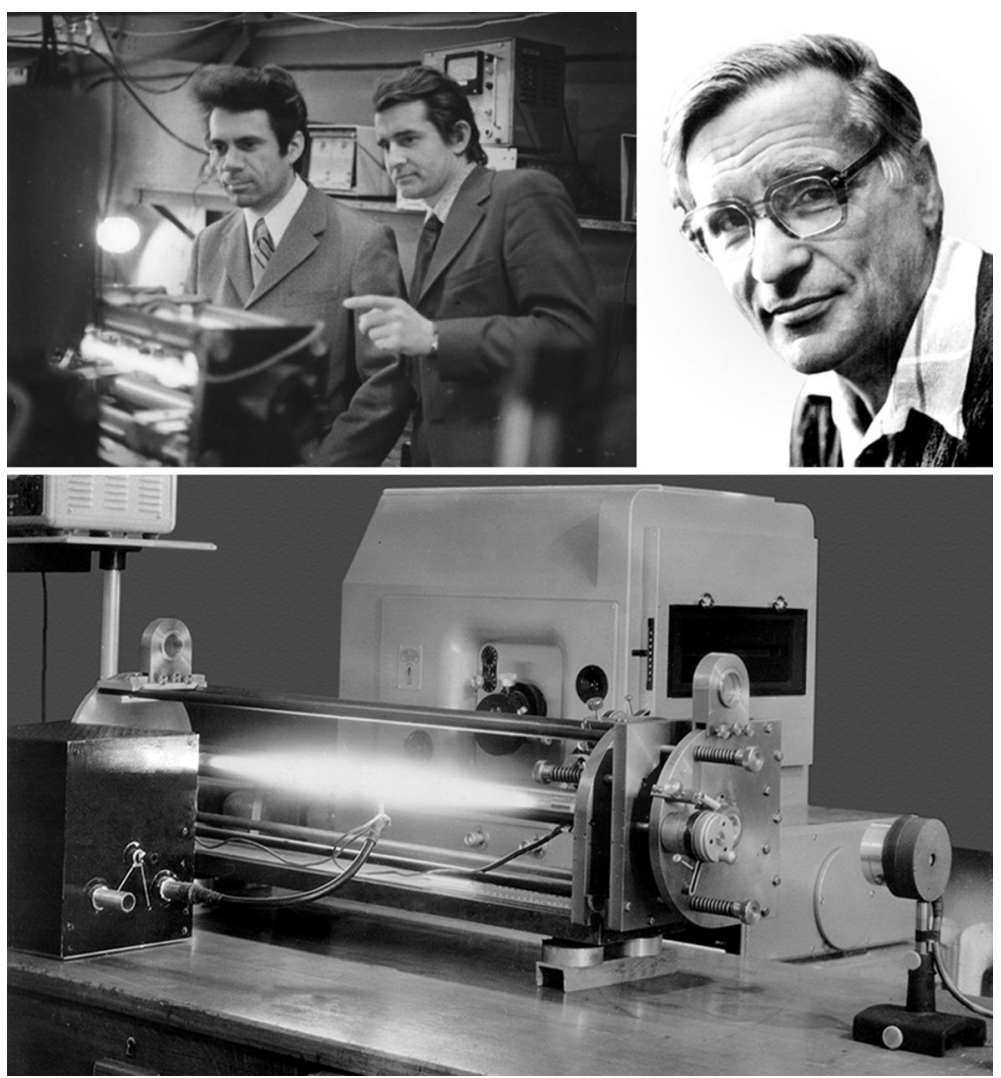

Fig. 13. Top left: Veniamin Chebotaev (1938-1992, left ), Sergei Bagaev (1941), both at the Institute of Laser Physics, and Sergei Rautian (1928-2009) at IAE (top right photo), the founders of new directions in nonlinear spectroscopy. Bottom the first laser realized in 1962 in Siberia (IRE). Credits: A. N. Polyakov; Yu. Troitski. Source: Photo-archive SO RAN, http://www. soran1957.ru.

and the physics of classical solitons and dispersion-managed solitons.* In laser physics, the institute is known for a $500 \mathrm{~W}$ argon-ion laser, a long fiber laser based on Rayleigh scattering. Important research programs are carried out at the IAE in gas spectroscopy, including nonlinear pump-probe spectroscopy (figure 13), lowtemperature high-current plasma, and light-induced effects in gases, as well as the physics of photorefractive crystals and of the dynamics of glasses on the basis of Raman scattering. The technology department develops architecture, system

* The term soliton refers to special kind of waves that can propagate undistorted over long distances and remain unaffected after collision with each other. Dispersion-managed solitons (in fibers) can accumulate more energy than classical solitons. 
solutions, mathematical models and software for data processing and computing systems of recognition, analysis and representation of information and control systems for complex dynamic processes. A 3-D simulator was developed for training jet pilots and cosmonauts (figure 14). Every ISS crew uses the simulator to practice spaceship docking, to familiarize themselves with the interior of the station and outside views through the ISS windows. During 1980s, the crews of the Soviet space shuttle Buran were trained on such a simulator.

A photo exhibition on the Akademgorodok's history, located near the Institute of Automation and Electrometry, was inaugurated in June 2013 to commemorate the fifty-fifth anniversary of the Soviet District of Novosibirsk, in which Akademgorodok resides. The exhibition includes twenty displays of black-and-white photographs (figure 6). Views of the institute buildings and residential areas under construction, vistas of Akademgorodok's streets and the Ob Sea, portraits of famous scientists, politicians, and public leaders who visited the place are presented along with images narrating the scientific and social life of the Novosibirsk Scientific Center.

Academician Koptiug Avenue is also the home of several institutes earlier forming the Institute of Geology and Geophysics (created in 1957). This was the first attempt to unite within a single research organization specialists of every major department of geology and geophysics. Academician Andrei Trofimuk (1911-1999), a prominent scientist in the area of geology and oil and gas prospecting, championed the foundation of this institute. He graduated from the Kazan State University (1933) and then worked in Bashkiria's oil industry. During the war, he discovered a major oil deposit nicknamed the Second Baku. In 1957, Trofimuk convinced Lavrentyev that Siberia might contain very large oil and gas deposit; indeed, Siberian geologists under his direction discovered two major oiland gas-rich areas in Western and Eastern Siberia. These discoveries stemmed from his work on the theory of oil and gas formation and on methods of geological prospecting. Trofimuk's publications on the mechanisms of gas hydrate accumulation became the scientific foundation of the officially registered discovery (coauthored with $\mathrm{N}$. Cherski and others) that natural gases may take a solid form of hydrates in the Earth's crust. Trofimuk's legacy still drives development of the V. Sobolev Institute of Geology and Minerology and the A. Trofimuk Institute of Geology and Geophysics; the main building of this institute is decorated with a memorial plaque in his memory. A lecture hall at the Novosibirsk State University and a street in Akademgorodok are named after him.

In 1958, the Central Serbian Geological Museum was founded at the Institute of Geology and Geophysics. Its two exhibit halls preserve a mineralogical collection of more than a thousand items, topical collections of rock samples and ores, and a collection of minerals synthesized at the institute's labs. The majority of samples were retrieved during field expeditions. The Museum's selection of fiftysix meteorites, as well as gemstones (including jasper, agate, charoite, lapis lazuli, jade) and native gold samples are especially valuable. Exhibits of the Museum 
have been loaned to many other countries, and it is actively frequented both by locals and visitors, including many students and foreign scientists.

To the left of Academician Lavrentyev Avenue at Academician Rzhanov Street are three physical institutes next to each other. The oldest, Khristianovich Institute of Theoretical and Applied Mechanics (ITAM), was established in 1957. Its first Director, Academician Sergei Khristianovich (1908-2000), belonged to a circle of remarkable Russian mechanics together with Nikolai Zhukovsky, Sergei Chaplygin, and Nikolay Kochin. Khristianovich made an enormous contribution to the development of several departments in mechanics, such as aero- and gasdynamics, mechanics of mountain ranges, the theory of plasticity, theory of filtration, and ecological power engineering. Khristianovich organized in Siberia an institute that examined problems of high-speed aerodynamics, shock waves, magnetic hydrodynamics, rock mechanics, and high-power systems. He supervised the development of a powerful facility for aerodynamic studies necessary in the design and testing of novel aircraft, which includes a turbo-compressor station and a world-class supersonic wind tunnel with high-performance measurement and computation equipment. Khristianovich, like Novikov, had disagreements with Lavrentyev, one of which prompted his return to Moscow in 1965. His name sank into oblivion for many years, but recognition of his accomplishments has recently been restored. Several scientific conferences have been held in his memory, his name was given to the Institute of Theoretical and Applied Mechanics, where a memorial plaque has been installed, and to a lecture hall at the Novosibirsk State University.

Today, the problems of aero- and gas-dynamics, physico-chemical mechanics, and mathematic modeling in mechanics are the primary research topics at the Institute of Theoretical and Applied Mechanics. Most of development at the institute is related to high-speed aircraft and is based on experimental and theoretical studies. The institute's experimental facility (gas-dynamic installations) enables advanced studies of both overall aerodynamic parameters of aircraft models and the fine structure of flows in order to improve understanding of laminar, turbulent, and detached flows at sub-, super-, and hypersonic speeds. The institute focuses its research on mathematical modeling in mechanics, air and gas dynamics, physical and chemical mechanics. One of the institute's brightest results is the phenomenon of cold spray deposition discovered in early 1980s by studying models describing a supersonic two-phase flow (gas + solid particles) in a wind tunnel.

The Rzhanov Institute of semiconductor physics concentrates on the physics of condensed media, including semiconductor and insulator physics and physics of low-dimensional systems; micro-, nanoelectronics, quantum computing, and the physical- chemical bases of micro-, nano-, opto-, acousto-electronic, and microsensoric technologies. The institute has several research and technology buildings in Akademgorodok. Anatoli Rzhanov (1920-2000), its first director, was badly injured in 1943 during World War II. Nevertheless, in 1948 he defended his PhD 




Fig. 14. Two examples of technology breakthroughs. Left pieces of copper-steel-brass (top), steel-duraluminium (bottom) welded by explosion at Lavrentyev Institute of Hydrodynamics. Right A 3-D visualization of the International Space Station (ISS) developed at the Institute of Automation and Electrometry. Sources: hydro.nsc.ru/techn1.php; Journal Science First Hand, http://sfh_49_6-21.pdf.

Thesis at Lebedev Physical Institute in Moscow and shortly after started work on the first Soviet transistor. In 1962, he moved to Novosibirsk Akademgorodok and established the Institute of Solid State Physics and Semiconductor Electronics, soon transformed into the Institute of Semiconductor Physics.

The Institute of Laser Physics is one of the youngest institutes in Akademgorodok, established in 1991. V. Chebotaev (figure 13) was its first director, and S. Bagaev is the second and current director. The Institute focuses its research on development of frequency standards and nonlinear spectroscopy. In 1991, the narrowest optical resonances were demonstrated by using Doppler-free spectroscopy. In 1994, the first optical clock based on a chain of several frequencystabilised lasers was created to measure a mid-infrared methane transition with the accuracy of $10^{-13}$.

The Voevodsky Institute of Chemical Kinetics and Combustion (Institutskaya Street 3) developed the electron spin echo spectroscopy with high resolution of weak magnetic electron-nuclear interactions. The technique is instrumental in the study of structure of traps for electrons, atoms, and radicals in irradiated matrices. The Siberian Center for Photochemical Studies (Lavrentyev Avenue 11) is formed through the joint efforts of the Budker Institute of Nuclear Physics and the Voevodsky Institute of Chemical Kinetics and Combustion (figure 15). Based on a far-infrared free-electron picosecond laser, which first achieved lasing in 2003, it provides experiments for physics, chemistry, and biology. Today, the laser has the highest average power in the spectral range between 100 and $200 \mu \mathrm{m}$. In 2015, its shortest wavelength will be shifted towards $20 \mu \mathrm{m}$.

Akademgorodok attracted famous Soviet artists and creators. Over different periods, it welcomed Konstantin Simonov, Andrei Voznesenski, Bella Akhmadulina, Alexander Solzhenitsyn, Bulat Okudzhava, Adron Mikhalkov- 


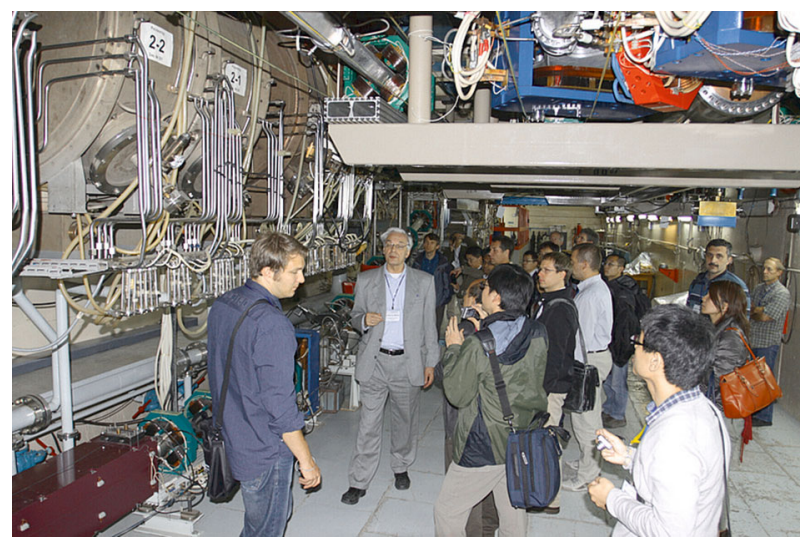

Fig. 15. Excursion to the Free Electron Laser at the Siberian Centre for Photochemical studies. Second from left: N. Vinokurov, one of the laser developers. Credit: N. Vinokurov.

Konchalovsky, Andrey Tarkovskii, and Eldar Ryazanov. In the 1960s, the young scientists Anatoly Burstein, Gennady Beznosov, and others championed the creation of a café and scientists' club called "Under the Integral"; currently, its former building at Academician Lavrentyev Avenue 16 is occupied by MDM Bank. In 1968, the club organized an all-union festival of amateur songwriters and performers-a so-called bardfest—attended by Alexandre Galich and other wellknown artists. Their songs were branded as subversive and anti-soviet; the club was shut down. In 2003, a memorial tablet in honor of Galich was installed on the building where the club used to reside.

After the festival and a joint open letter known as the "Letter of 46" written by the Akademgorodok scientists against secret political trials in the Soviet Union, the Novosibirsk Communist Party committees started an ideological campaign to "educate" the scientific staff of Akademgorodok. This campaign signaled the end of Khrushchev's Thaw. Its scientists were informed that Akademgorodok's scientists was no "island of freedom," but only one of many city districts of Novosibirsk. Meetings were held at institutes at which the letter's authors were forced to publically recant their actions. They were punished by the Communist Party organization by expulsion, reprimands, and warnings, although Lavrentyev and the directors of Akademgorodok's institutes did everything they could to prevent fatal consequences to the scientific careers of the letter authors. Not without success: for instance, one of the signatories, Anatoli Shalagin, later became an academician and Director of the Institute of Automation and Electrometry.

The Lavrentyev Institute of Hydrodynamics is situated on the other side of the avenue. The first Institute director (1957-1976) was Mikhail Lavrentyev. Today, the institute focuses its activity on mathematical problems of continuum 

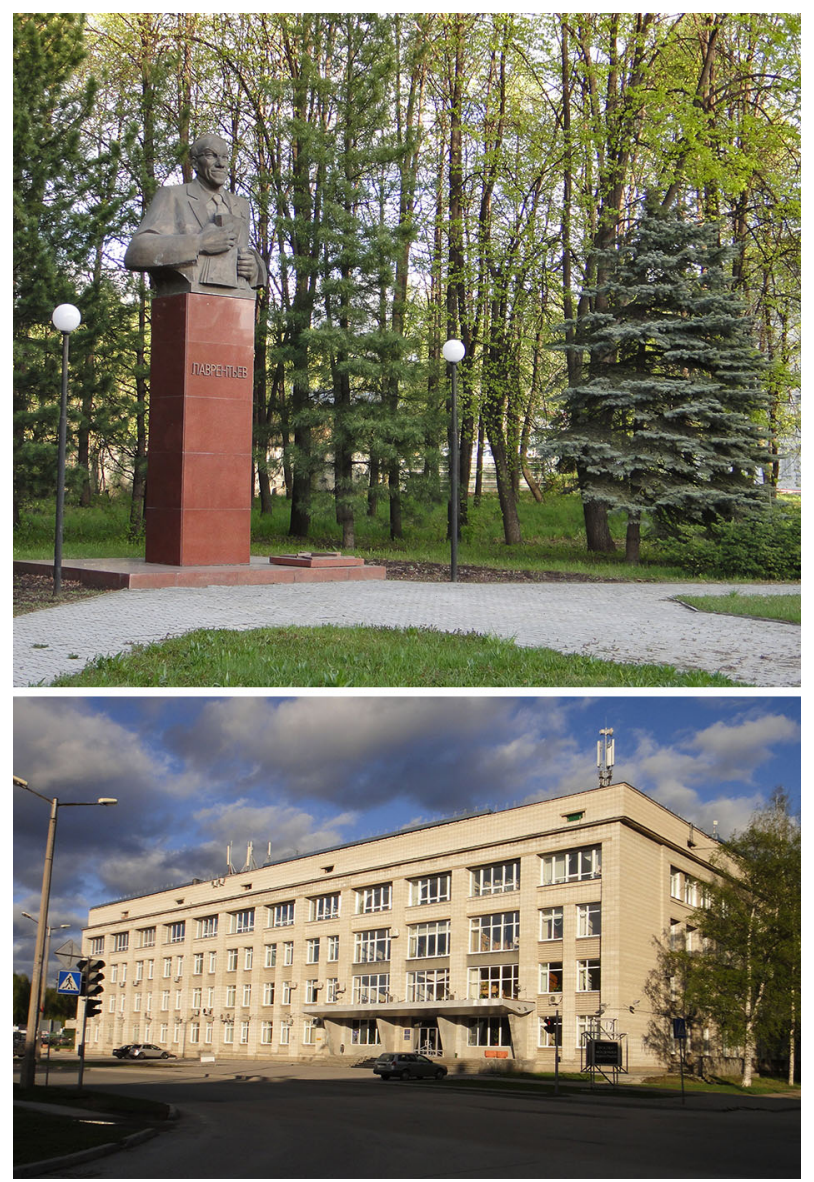

Fig. 16. Top Lavrentyev's monument; bottom the Presidium of SB RAS. Credit: NK.

mechanics, on the physics and mechanics of high-energy processes, electrophysics, on fluid and gas dynamics, and on solid mechanics. The most significant scientific results include the development of methods of group analysis of differential equations in continuum mechanics, the theory of nonlinear waves in continuous media, theories of high-temperature strength (creep) and elastic-plastic deformation of structurally-nonuniform materials and constructions, mathematical models of wave flows of stratified liquid and joint movement of subsoil and surface waters, models of initiation, structure, and propagation of detonation in gas and heterogeneous systems. New phenomena have been identified in spin detonation, in explosive processes (figure 14), including welding by explosion, and in the formation of ultradispersed diamond. 

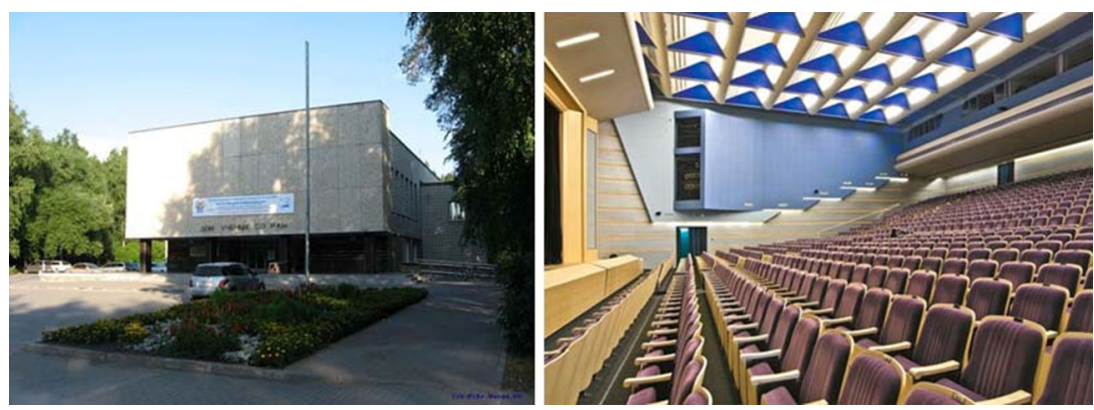

Fig. 17. Left part of the House of Scientists; right its large hall in the right part of the building. Source: http://www.dusoran.ru/events/location/big-hall.html.

At the ninety-degree turn of Lavrentyev Avenue towards Morskoy Avenue, we see the Lavrentyev memorial and the Presidium of the Siberian Branch of the Russian Academy of Sciences (figure 16). The street to the left leads to a wooden Orthodox Church. Midway to the church, we can see, academicians' houses on Akademicheskaya Street and on Voevodskogo Street. This brings us back to Morskoi Avenue, one of the most picturesque in Academgorodok, which leads, on the right, to the Museum of Science and Technology (Detsky Proezd 15). The museum welcomed its first visitors in 2006. Its main function is to preserve, study, and popularize the cultural heritage in science and technologies. The Museum's staff develops their exhibit repository in four directions: instrumentation and technology of scientific experiment, transportation, radio and communications, and cinema and photography technology.

The left turn in the middle of Morskoi Avenue, Zolotodolinskaya Street, leads to the Botanical Garden of the Serbian Academy of Sciences (approximately 20 min on foot), and to Lavrentyev's house (Zolotodolinskaia, 75). Today, this is the museum of the Serbian Academy of Sciences. It is also an example of the temporary houses built in the end of fifties for the founders of Akademgorodok. Before visiting that house, however, one should visit the Exhibition Center (Zolotodolinskaia Street 11), which presents the most recent achievements of the institutes of the Novosibirsk Akademgorodok, opened to the public in 1998 and subsequently renovated in 2007. The main objective of the Exhibition Center is to assist the institutes in promoting and commercializing their technologies. The Center organizes traveling exhibitions of the products of the institutes both in in Russia and abroad and holds seminars and presentations covering recent research and development efforts attended by interested commercial companies. The Exhibition Center also works to popularize the advances of Siberian science. An important cultural and communication role in Akademgorodok is played by the House of Scientists, a center for scientific and social events (Morskoy Avenue 23, figure 17). The French President Charles de Gaulle was the first foreign visitor to 

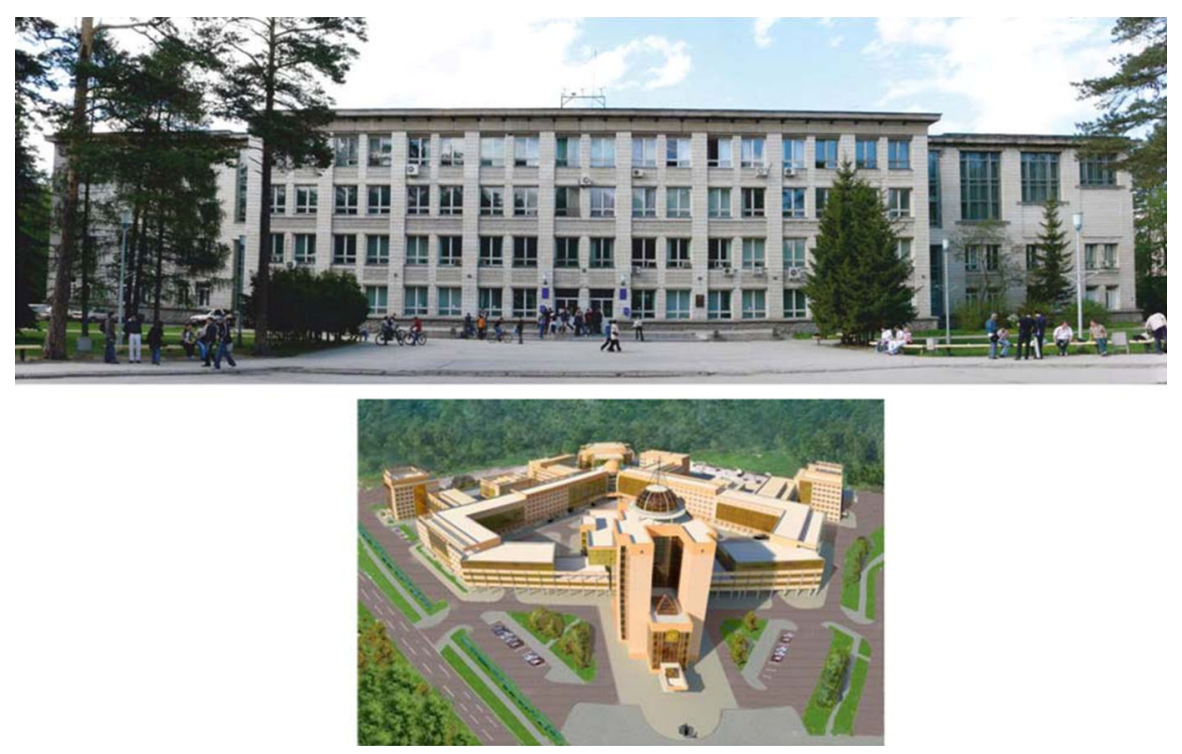

Fig. 18. Novosibirsk state university: the current main building (top) and a new main part of NSU under construction (bottom). Source: http://www.nsu.ru.

this center. The first and the only personal exhibition of the soon-to-be-"disgraced" painter Mihail Shemiakin was held at the House of Scientists in 1967 (he was exiled from the USSR in 1971). In 1968, not long before his own immigration, poet and playwright Alexandre Galich gave his last concert on the stage of the House of Scientists during a festival of amateur songwriters and singers.

The way down along Ilyicha Street leads through the cultural center of Academia, the shopping center Torgovyj Tsentr and Hotel Zolotaia Dolina, to the Novosibirsk State University. This university (Pirogova Street 2, a continuation of Ilyicha Street; figure 18), was founded in 1959. Its first head was I. Vekua. From the very beginning it focused, at least in the natural sciences, on preparing specialists for the young Novosibirsk scientific center. The official opening of the University took place on September 26, 1959 at the Opera and Ballet Theater (figure 5). The first department of the University was the Department of Natural Sciences, which combined mathematics, physics, mechanics, biology, chemistry, and geology. Between 1960 and 1967, these disciplines were transformed into departments. In December 1963, the first graduates of the Novosibirsk State University, including twenty-six physicists, twenty-four mathematicians, and ten researchers in mechanics received diplomas. Students study for their diploma at the RAS research institutes, while the teachers and professors of the university are the members of these institutes. There is also a research division at NSU. The university today has more than 
5,000 students at thirteen departments. As in the early times of the NSU, the Physics Department remains among the best university departments. A new main building (figure 18) will be ready in 2015 .

The Lavrentyev School of Physics and Mathematics, situated at the university campus, was founded in 1963, aiming to provide more in-depth education of highschool students. Most of the students at the School are winners of Siberian physical, mathematical, and chemical Olympiads. The majority of the school graduates have also studied at NSU. Pirogova Street passes the University student housing and crosses Lavrentyev Avenue exactly at the point where the billboard stands inscribed with the famous words of Mikhail Lomonosov, closing thus the tour of Akademgorodok. From the House of Scientists, it takes fifteen minutes on foot down Morskoy Avenue to reach the Ob beach, during summer a lovely place for young people, complete with disco and bars.

\section{A Few Recommendations to Visitors of Akademgorodok}

The best time to visit Akademgorodok is from May to September; winters can be cold for foreigners without prior acclimatization. It is best to fly from Europe directly to Novosibirsk, bypassing Moscow. Many Europeans dream of travelling across Russia via the Trans-Siberian Railway, but a trip from Moscow to Novosibirsk by fast train takes only fifty-six hours. From Tolmachevo Airport or Novosibirsk Railway Station (figure 5) to Akademgorodok takes approximately one hour by taxi, the best means of transport in Novosibirsk. Use early morning or late evening hours for this trip, which in daytime may take longer because of traffic jams. To arrange a scientific tour, we recommend contacting in advance S. Zakovriashin, the head of the Council of Foreign Affairs of the RAS Presidium, phone +7 38333019 56, e-mail zakov@sbras.nsc.ru.

\section{Acknowledgments}

The authors are grateful to the help of V. Zarko, S. Novopashin, S. Khorev, A. Maslov, and N. Vinokurov. The paper was prepared with the assistance of the alumni and alumnae association Soyuz of Novosibirsk State University.

Open Access This article is distributed under the terms of the Creative Commons Attribution License which permits any use, distribution, and reproduction in any medium, provided the original author(s) and the source are credited.

\section{References}

${ }^{1}$ I. V. Kondratyuk, The Conquest of Interplanetary Space (Novosibirsk: Y. Kondratyuk Foundation, 1997)

${ }^{2}$ D. Sheridan, "If there is any idea we must push, it's this one," Life 66, no. 10 (1969), 20 
${ }^{3}$ J. Bellissard and D. L. Shepelyanski, "Boris Chirikov, a Pioneer in Classical and Quantum Chaos," Annales de l'Instut Henri Poincaré 68, no. 4 (1998), 379-380

4. A. P. Aleksandrov, L. M. Barkov, S. T. Belyaev, Ya B. Zel'dovich, B. B. Kadomtsev, A. A. Logunov, M. A. Markov, D. D. Ryutov, V. A. Sidorov, A. N. Skrinskii, B. V. Chirikov, "Academician Gersh Itskovich Budker (obituary)," Soviet Physics Uspekhi, 21, no. 4 (1978), 369-372. doi:10.1070/PU1978v021n04ABEH005547.http://www.turpion.org/php/paper.phtml? journal_id=pu\&paper_id=5547.

Department of Physics

Ludwig Maximilian University of Munich

Am Coulombwall 1

85748 Garching, Germany

e-mail: apolonskiy@lmu.de 